\title{
Editorial
}

\section{School and Vulnerable Families}

In many ways, a person's educational path depends on their family background. Families' living conditions and current living situation affect the educational opportunities of children and young people, whose lives are influenced by the problems, inequalities or privileges that stem from their origins.

For example, there are differences in families' educational aspirations, i.e., their expectations and demands regarding the children and young people's success in school, and this undoubtedly affects their educational path. In the same way, parents have very different opportunities and a varying capacity for helping their children with school matters. Finally, the sociocultural and habituated dispositions resulting from the way families live their everyday lives are highly relevant to access to education. The family and the school are thus profoundly interdependent.

Within every family, a "family-specific habitus" develops, which depends on how families are involved in their milieu and extends beyond socialisation processes to produce a kind of "basic education", comprising of specific capabilities for action, preferences and adopted lifestyles (Brake \& Büchner, 2011; Ecarius 2013; Grundmann et al., 2010). These family-related adopted lifestyles correspond to the behavioural expectations of schools in varying degrees. The expectations include factors such as students' rationality, cognitive approach, diligence, forward planning and capacity for considered communication. Depending on their milieu, families may meet these behavioural expectations to various extents, leading some students to have problems fitting into the school system (Lange \& Xyländer 2011, 23; Sting 2016, 128). At the same time, families' habituated dispositions meet with varying levels of social acceptance, greater or lesser degrees of social recognition and prestige. Bourdieu's studies on the socially differentiating function of the habitus showed that family lifestyles are one element of a hierarchical set of social positions that produce unequal educational opportunities (Bourdieu, 1994). For the acquisition of legitimate education, an unequal background in terms of habitus goes hand in hand with an unequal socioeconomic background, which considerably limits the opportunities of low social status families to attain advanced levels of education.

Recent international educational studies have all shown a connection between family background and scholastic success. In the countries these studies investigate, links can be seen between the social status of children and young people's families and their educational opportunities. Although these links vary 
in extent, one thing is clear: education and social support systems manage to reduce background-related educational inequalities to varying degrees (c.f., for example, Hartas, 2011; OECD, 2016, 74-89; OECD, 2016a, 63-78). One group that is the focus of particular attention is vulnerable families.

This special edition of the CEPS Journal, dedicated to vulnerability, clearly reflects the needs of our time: it comes at a point when the state is shirking its responsibility towards the vulnerable and underprivileged, when discourse on shouldering personal responsibility for one's own fate has intensified, and when responsibility for vulnerable families has shifted onto non-governmental, volunteer and philanthropic organisations.

Vulnerable families usually suffer from two levels of disadvantage: firstly, they mostly have a low social status, and secondly, they are affected by acute or chronic problems or crises that impact their involvement in and willingness to deal with school requirements. The contributions in this edition address the pressing need for collective responsibility and the concerted action of all experts and institutions in the fields of education, social care and health.

Contemporary work on vulnerability is currently facing a number of contradictions. Even though the understanding that priority should be given to policies and approaches that address the needs of the vulnerable in a holistic manner has been widely accepted, the various services and organisations very rarely communicate with one another, and infrequently share their experiences and findings or discuss the challenges and dilemmas that they encounter; they seldom establish common, intersecting areas of work or interdisciplinary response practices.

Furthermore, everyone - from academics and policymakers, to practitioners and service providers - agrees that vulnerability is a result of extremely complex situations; at the same time, there is recognition that every situation is unique. However, this complexity and uniqueness is systematically ignored both in professional practice and in research. The third contradiction is that, although we are all aware that the participation of family members plays a central role in defining their own situation and the responses to it, methods that attempt to elicit their perceptions and points of view, let alone allow their perceptions to influence professional approaches and policies, are rarely used (Te Riele \& Gurur, 2015). It is therefore clear that the challenges facing contemporary work in the field of vulnerability lie in creating new and innovative approaches that stem considerably more from the needs and specificities of the family, and rectify the current dispersal of assistance to vulnerable families by merging and creating a more synergistic approach.

Reflecting this framework, the present issue opens with a consideration of the category of family vulnerability. Petra Bauer and Christine Wiezorek's 
"Vulnerable Families: Reflection on a Difficult Category" offers empirical, qualitative insights into the process of supporting a family considered to be in need of professional intervention. Through evidence-based interactions, we witness how standardised professional concepts and insensitive professional norms about how a family functions can damage a family's basic right to be recognised as a unique entity that requires an individual approach and coping style to successfully fulfil the needs of their children.

The second article, written by Nada Turnšek, Olga Poljšak Škraban, Špela Razpotnik and Jana Rapuš Pavel, "Challenges and Responses to the Vulnerabilities of Families in a Preschool Context", begins by pointing out that, in modern times, educational institutions are attributed the role of an equaliser of educational opportunities, and are a key instrument in promoting the social inclusion of children. The idea of education as a social investment strategy reduces children merely to "pupils"; consequently, many families - particularly vulnerable families - are deemed unable to ensure an adequate environment in which to raise their children. Researching the role that kindergartens play in dealing with vulnerable preschool children and their families revealed the following paradox: kindergartens often try to respond to a vulnerable family's very complex and non-standard situation by using standard processes and conventional procedures. At the same time, kindergarten workers have also been found to respond creatively and inventively, using many flexible responses to the needs of vulnerable people, thus indicating a tendency towards creating innovative approaches.

Nina Mešl and Tadeja Kodele’s "Co-Creating Desired Outcomes and Strengthening the Resilience of Multi-Stressed Families" also reveals that by working within families in their homes and forming relationships based on cooperation and partnership it is possible to overcome the current, often unsuccessful attempts to contend with a child's poor school performance. The plural case study shows that it is possible to establish co-creative working relationships founded on the commitment of all participants to take part in a joint working project. In such a project, the process of helping the family deal with a child's poor school performance is co-created in a safe environment of cooperation; in a relationship built on partnership, all family members are encouraged to express their desired outcomes and to contribute to solutions. A key part is also played by casting the child in the role of an expert concerning his/her own experience, one whose voice is protected and appreciated, and is regarded as important for collaboration in order to fulfil the desire for success.

The fourth paper, "Rethinking the Role of Pedagogical Assistants: Establishing Cooperation between Roma Families and Schools in Serbia”, by Jelena 
Starčević, Bojana Dimitrijević and Sunčica Macura Milovanović, examines the risks and challenges related to the cooperation of Roma parents/families with pedagogical assistants working with Roma pupils. The paper offers insight into ways of overcoming the pupils' struggles and difficulties related to school work, as well as the school's expectations, standards and norms, while also focusing on the obstacles inherent in these relations. These obstacles exist on both sides and concern not only the aspirations, knowledge, culture and strategies of the parents and families, but also the requirements, prejudice, stereotypes and discriminatory treatment of the institutions. The newly introduced education policy measure of pedagogical assistants in Serbia aims to support the learning and social participation of Roma pupils and establish cooperation between school staff and Roma parents. However, the authors perceive further segregation of Roma pupils and reduced engagement of teachers when it comes to establishing cooperation. They propose a framework for defining and understanding the roles of teachers and pedagogical assistants built on an intercultural perspective, which includes two main concepts: intercultural sensitivity and intercultural competence with cognitive, affective and behavioural characteristics. Furthermore, they strongly emphasise the necessity of perceiving cultural differences in accordance with the ethnorelative worldview, both on the part of the teachers and pedagogical assistants.

Ulrike Loch's "Between a School-Centred Focus on Education and Family Needs" continues with the theme of vulnerable families in relation to schools, their expectations and standards. Loch first draws the reader's attention to the fact that the education system's social selectivity has a crucial impact on the social exclusion of children even before they enter the school. The evidence in this paper goes hand in hand with that presented by "Challenges and Responses to the Vulnerabilities of Families in a Preschool Context" earlier in this issue. The author uses her own experiences of accompanying children's social care service staff in Germany and Austria as an ethnographer while they processed child protection cases. The article focuses on families with mentally ill parents and reveals how the parents' mental illness is seen to affect the children, and what support the families in question require. Once again, stress is placed on the need for taking an individual family's specific situation into account in the educational discourse of not only child and youth welfare services but also within the frame of formal education systems. Loch outlines how a school-centred understanding of education affects children, while at the same time having an impact on the youth welfare practice/support processes within the families' context. The reader gains valuable insight into a case process, while the author warns that the current discourse on education and the social 
living environment of families with mentally ill parents needs fundamental examination.

In "Lifeworld-Oriented Family Support", Špela Razpotnik, Nada Turnšek, Jana Rapuš Pavel and Olga Poljšak Škraban demonstrate that overcoming conventional approaches is possible after all, but only with a paradigm shift. The article presents a newly developing approach of "supportive entering into the family", based on the lifeworld-oriented social pedagogy paradigm. The fact that professionals are present in the family's everyday lives makes it possible for the family's life experiences to become the focal reference point when it comes to determining successful responses to the difficulties they face. In such an approach, the discourse of deficit is replaced by the discourse of resources: professionals and volunteers draw from the resources that the individual, family or community do in fact possess, rather than concentrating solely on what is inadequate or problematic. When contemplating future possibilities, the authors particularly highlight the increased role played by a support network of volunteers. They find that practices need to become more focused on the family, and that more attention needs to be paid to prioritising the support role over the supervisory role.

In the Varia section, Katarina Aškerc's article entitled "University Teachers' Opinions about Higher Education Pedagogical Training Courses in Slovenia" poses relevant questions as to the pedagogical qualifications of university teachers, which should - considering the current massive influx of students into higher education - encourage their more comprehensive study. Aškerc argues that a long-lasting training process, such as the one provided by pedagogical training courses for university teachers, produces positive effects on teachers' pedagogical thinking and their understanding of teaching and learning. The author also suggests the use of a combination of various methods in habilitation procedures in Slovenian higher education: in addition to the "probationary lecture" and sustained pedagogical training, she proposes some optional methods, such as various elective pedagogical training courses for university teachers, as well as teaching portfolios, student interviews, class observations and peer evaluations.

In the second paper in the Varia section, entitled "The Impact of Active Visualisation of High School Students on the Ability to Memorise Verbal Definition", Anamarija Šmajdek and Jurij Selan proceed from the proposition that visuality plays a central role in human multimodal communication competence development. They investigate pertinent questions from the field of educational psychology concerning the meaning of the simultaneous use of several senses in learning. Their empirical study proves that active visualisation 
indeed provides general cognitive benefits for students in memorising and understanding in different school subjects. Additionally, they indicate various other dimensions of the role of visualisation in education, thus stressing that the education system needs to cultivate artistic/visual literacy more extensively.

\section{Alenka Kobolt, Stephan Sting and Nada Turnšek}

\section{References}

Bourdieu, P. (1994). Raisons pratiques. Sur la théorie de l'action [Practical reason. On the theory of action]. Paris: Editions du Seuil.

Bracke, A., \& Büchner, P. (2011). Bildungsort Familie. Habitusgenese im Netzwerk gelebter Familienbeziehungen [Family as a place of education. Genesis of habitus in the network of lived family relations]. In A. Lange \& M. Xyländer (Eds.), Bildungswelt Familie [Educational world of the family](pp. 142-166). Weinheim, Munich: Juventa.

Ecarius, J. (2013). Familie-Identität-Kultur [Family-Culture-Identity]. In M. S. Baader, P. Götte, \& C. Groppe (Eds.), Familientraditionen und Familienkulturen [Family traditions and family cultures] (pp. 53-70). Wiesbaden: Springer VS.

Grundmann, M., Bittlingmayer, U. H., Dravenau, D., \& Groh-Samberg, O. (2010). Bildung als Privileg und Fluch - zum Zusammenhang zwischen lebensweltlichen und institutionalisierten Bildungsprozessen [Education as privilege and bane - about the connection between educational processes in the life-world and in school institutions]. In R. Becker \& W. Lauterbach (Eds.), Bildung als Privileg [Education as privilege] (pp. 47-74). Wiesbaden: Verlag für Sozialwissenschaften. Hartas, D. (2011). Families' social backgrounds matter: socio-economic factors, home learning and young children's language, literacy and social outcomes. British Educational Research Journal, 37(6), pp. 893-914.

Lange, A., \& Xyländer, M. (2011). Bildungswelt Familie: Disziplinäre Perspektiven, theoretische Bestimmungen und Desiderate der empirischen Forschung [Educational world of the family: Perspectives of disciplines, theoretical approaches and empirical research]. In A. Lange \& $\mathrm{M}$. Xyländer (Eds.), Bildungswelt Familie [Educational world of the family] (pp. 23-94). Weinheim, Munich: Juventa.

OECD (2016): Education at a Glance 2016: OECD Indicators. Paris: OECD Publishing. OECD (2016): Low-Performing Students: Why They Fall Behind and How to Help Them Succeed. Paris: PISA, OECD Publishing.

Sting, S. (2016). Bildung im sozialen Raum. Überlegungen zu einer sozialpädagogischen Konzeption von Bildung [Education in social space. Reflections on a social pedagogical concept of education]. Zeitschrift für Sozialpädagogik, 14(2), 118-139.

Te Riele, K., \& Gorur, R. (Eds.) (2015). Interrogating conceptions of "vulnerable youth" in theory, policy and practice (external link). Rotterdam: Sense Publishers. 